\title{
The Implementation of the 2012 Mental Health Strategy for Canada Through the Lens of FASD
}

\author{
Tara Anderson, Mansfield Mela, \\ University of Saskatchewan \\ Michelle Stewart \\ University of Regina
}

\begin{abstract}
It is the current authors' perspective that the successful implementation of Changing Directions, Changing Lives, which seeks to improve mental health and well-being in Canada, cannot be realized effectively without considering FASD. Given that $94 \%$ of individuals with FASD also have mental disorders, practitioners in the mental health system are encountering these individuals every day. Most mental health professionals have not been trained to identify or diagnose FASD, and therefore it goes largely "unseen," and individual treatment plans lack efficacy. Implementation of FASD-informed recommendations, such as those of the Truth and Reconciliation Commission of Canada (2015), can provide a more effective approach to mental health services and improve mental health outcomes.
\end{abstract}

Keywords: Fetal Alcohol Spectrum Disorder, FASD, prenatal alcohol exposure, mental health, mental disorder, FASD-informed care

\section{RÉSUMÉ}

Il est de notre point de vue que la mise en œuvre de Changer les orientations, changer des vies, qui vise à améliorer la santé mentale et le bien-être au Canada, ne peut être efficacement réalisé sans tenir compte de l'ETCAF. Compte tenu de 94 pour cent des personnes atteintes de l'ETCAF ont aussi des troubles mentaux, le système de santé mentale se heurte à ces personnes tous les jours. La plupart des professionnels de la santé mentale ont pas été formés pour identifier ou diagnostiquer l'ETCAF, ce qui signifie qu'il va en grande partie "invisible" et les plans de traitement donnés aux personnes manquent d'efficacité. La mise

Tara Anderson, Department of Psychiatry, College of Medicine, University of Saskatchewan, Saskatoon, Saskatchewan; Mansfield Mela, Department of Psychiatry, College of Medicine, University of Saskatchewan, Saskatoon, Saskatchewan; Michelle Stewart, Justice Studies, University of Regina, Regina, Saskatchewan.

Correspondence concerning this article should be addressed to Tara Anderson, Department of Psychiatry, College of Medicine, University of Saskatchewan, 103 Hospital Drive, Saskatoon, SK S7N 0W8; phone 306-844-1335. Email: tara.anderson@usask.ca 
en œuvre des recommandations de l'ETCAF inclus, tels que ceux observés dans la Commission vérité et réconciliation du Canada (2015) peut fournir une approche plus efficace de services de santé mentale et de produire de meilleurs résultats positifs en matière de santé mentale.

Mots clés : le trouble du spectre de l'alcoolisation foetale, l'exposition prénatale à l'alcool, santé mentale, troubles mentaux

In 2012, the significant step of putting out a milestone Mental Health Strategy in Canada was taken with the release of Changing Directions, Changing Lives (Mental Health Commission of Canada, 2012), herein referred to as "the National Strategy." The approach sought to be inclusive, especially for those with severe and complex challenges. It is now time to review the progress made and expand the inclusiveness of the National Strategy. Transforming and improving the mental health system can best be achieved when it accounts for everyone the system aims to help. It is our perspective that this effort would benefit from an approach that incorporates an understanding of Fetal Alcohol Spectrum Disorder (FASD). This is in line with the view of the National Strategy, which emphasizes that for the mental health system to be of a high quality, it must support all people "regardless of their origin, background, experience or circumstances" (Mental Health Commission of Canada, 2012, p. 10).

\section{FASD AND MENTAL HEALTH}

According to the recently updated Canadian Diagnostic Guidelines, FASD is a term used to "describe a broader spectrum of presentations and disabilities resulting from alcohol exposure in utero" (Cook et al., 2015, p. 10). Since its initial description over four decades ago, FASD has often primarily been classified as a brain abnormality, but more recent evidence points to FASD as, in fact, a whole-body disorder, presenting with an alarming rate of medical comorbidities (Popova et al., 2016). Although there are inherent challenges to knowing the prevalence of FASD, in Canada, estimates are approximately 1 in 100 live births (Stade et al., 2008; Thanh, Jonsson, Salmon, \& Sebastianski, 2014). Rates estimated from the United States, parts of Western Europe, Africa, and other areas of the world are as high as $2 \%$ to $5 \%$ of the population (May et al., 2009; Roozen et al., 2016). In addition to the aforementioned updates to the Canadian FASD diagnostic guidelines of 2015 (Chudley et al., 2005; Cook et al., 2015), FASD has also recently been recognized as a diagnosable mental disorder in the fifth edition of the Diagnostic and Statistical Manual of Mental Disorders (DSM-5; Neurodevelopmental Disorder Associated with Prenatal Alcohol Exposure, 315.8 [F88]; and Neurobehavioral Disorder Associated with Prenatal Alcohol Exposure [Section III]; American Psychiatric Association, 2013). As there continues to be new clarity established regarding the diagnosis of FASD, and with its DSM classification as a mental disorder, the timing is ripe to better position strategic approaches to addressing FASD and mental health as part of an overall commitment to inclusivity.

To have a robust understanding of FASD requires a full recognition of the implications of mental disorder, given that mental disorder is the most commonly experienced "secondary disability" for up to $94 \%$ of individuals with FASD (Streissguth, Barr, Kogan, \& Bookstein, 1996). Individuals with FASD are at an elevated risk for suicidality. It has been reported that $43 \%$ of adults with FASD have threatened to 
commit suicide, and approximately $23 \%$ have attempted suicide (Streissguth et al., 1996). Another study further broke suicide attempt prevalence down by age and found rates of $3 \%$ in children aged 6 to 11 years, $12 \%$ in youths aged 12 to 20 years, and 23\% in adults aged 21 to 51 years (Huggins, Grant, \& Streissguth, 2008). Substance use concerns are also extremely common for those exposed to alcohol prenatally (Yates, Cadoret, Troughton, Stewart, \& Giunta, 1998). 53\% of males and 70\% of females who were exposed to alcohol prenatally have substance use concerns as adults, which is over five times the rates seen in the general population (Streissguth et al., 1996). Mental disorder occurs across the lifespan for individuals with FASD (O’Connor \& Paley, 2009), insofar as it is possible to know, given that FASD has been formally diagnosed only since the mid-1970s (Jones \& Smith, 1973).

Although the relationship between psychiatric risk and FASD is well established, the mental health system has generally not embraced the disorder. This has derailed the cohesive benefit expected to accrue from joint understandings of the relationship between mental illness and FASD. The resulting, somewhat irrelevant, discussion focuses on whether the two are the same and demands a determination of the role of FASD in those who present with mental health challenges, or vice versa. The difficulty of deciphering whether FASD is a risk factor, the major or a mild etiological factor, or a separate, unrelated disorder has created many challenges for how FASD fits into service delivery models. The significance of the relationship between FASD and mental health is therefore missed by many professionals (Fast \& Conry, 2011). The unsteady relationship the DSM has had with FASD over the years reflects the ambivalence that the psychiatric community has had to addressing FASD, specifically in its approach to intervening from a patient, service, epidemiological, or public policy perspective. Current Canadian curriculums of medical school and psychiatric training programs are devoid of or contain inadequate content on FASD (Arnold et al., 2013).

When considering diagnosing FASD and mental disorder, there are challenges associated with the implicit diagnostic processes when both are present. McLennan (2015) emphasizes that "it is also critical to retain attention on the relative impacts of multiple etiological factors contributing to mental health and to be wary of approaches emphasizing single risk factor models" (McLennan, 2015, p. 589). The relationship between mental disorder and FASD is intricately complex and appears to be reciprocally linked. The complexity of diagnosing a mental disorder in individuals prenatally exposed to alcohol can be compounded by existing cognitive and maladaptive behavioural difficulties. The currently poorly understood interactions of genetic and environmental influences to the exposure of varying levels of alcohol exposure in utero can also confound the process for diagnosing mental disorders in this population. Furthermore, when considering the process for FASD diagnosis in adults (in comparison to children and youth), diagnosis is multifaceted and may be impeded by the unavailability of the mother to confirm prenatal alcohol exposure, the absence of birth records, and indistinct facial features (Chudley, Kilgour, Cranston, \& Edwards, 2007).

Unfortunately, the vast majority of mental health professionals do not have training to recognize the FASD that they encounter in their clinical practice (O'Connor \& Paley, 2009). This lack of recognition can often result in FASD going undiagnosed or in a misdiagnosis. A recent study of 547 foster and adoptive youths found a missed FASD diagnosis rate of $80.1 \%$ along with a misdiagnosis rate of $6.4 \%$ (Chasnoff, Wells, \& King, 2015). A misdiagnosis in childhood is common, as children with challenging behavioural profiles may more easily be screened for other conditions such as Attention Deficit Hyperactivity Disorder (ADHD) and Oppositional Defiant/Conduct Disorder, learning disabilities, or communication disorders 
(Nash, Koren, \& Rovet, 2009; Nash et al., 2006). Once an individual receives a misdiagnosis, the prospect for appropriate understanding of the impairments and commonly experienced comorbidities of FASD can easily go unexplored.

The therapeutic approaches used to treat mental disorders and substance use concerns in individuals with an FASD diagnosis commonly lack efficacy if they do not account for the FASD. For example, when discussing the pharmacological treatment of addictions in FASD, Grant, Brown, Dubovsky, Sparrow, and Ries (2013, p. 87) emphasize that "failure to consider the possibility of FASD in treatment planning may result in treatment failure and/or relapse." In their discussion of effective treatments for substance abuse, Rutman, Poole, Hume, Hubberstey, and Van Bibber (2014) advocate for FASD-informed theoretical frameworks, methodologies, and programs. Approaches that make specific considerations for the challenges and brain differences associated with FASD are logical and in line with the clinical understanding of the disorder, yet are unfortunately not typical of the experiences of individuals living with FASD in Canada.

It is this absence of recognition and accommodation for FASD in mental health systems that can, at least in part, account for the regularity with which these individuals encounter trouble with the law. It is the combination of FASD-related challenges, the common occurrence of mental disorder, as well as the psychosocial status of many of those affected that is believed to contribute to a biological and neurophysiological vulnerability to criminality. More specifically, differences in domains such as neurocognition, adaptive function, and social skills, in combination with associated mental disorder, substance use concerns, and childhood adversity (all of which can be frequently experienced by those with FASD) are all factors associated with an increased risk for criminal behaviour (Fast, Conry, \& Loock, 1999; Roach \& Bailey, 2009). Approximately $60 \%$ of those with FASD over the age of 12 have had interface with the legal system, and $40 \%$ of adults with FASD have been incarcerated (Streissguth et al., 1996). Canadian youths with FASD versus those without it were 19 times more likely to be incarcerated (Popova, Lange, Bekmuradov, Mihic, \& Rehm, 2011). But, again, appropriate understanding, supports, and services are often not available. This can be the result of limited community capacity or resources, but it can also be the direct result of not correctly recognizing the disability. In the absence of appropriate supports, this risk increases. The current state of affairs presents an opportunity to intervene. Identification, diagnosis, and understanding of the complex problems of these individuals are essential if appropriate management strategies are to be established. In recognition of the risk, need, and responsivity principles of the effective management of individuals with offending behaviour, comprehensive assessments of neurocognitive function and comorbidity are the prerequisites for appropriate support (Chapman, 2008).

\section{STRATEGIC DIRECTIONS IN FASD}

The strategic directions envisioned by the National Strategy (Mental Health Commission of Canada, 2012) include harnessing multilayer, community-based, and evidence-informed peer and social support. Comprehensive services offer the best chance for mental health care. While the model of care and recovery is widely considered to be the ideal outcome in mental health, FASD is a lifelong disability from which one does not "recover" (although the principles of care and continued progress are still attainable and worth aspiring to). The full range of mental conditions, contributory factors, and possibilities for complications should be factored into the services and service-delivery approach. The services will thus be best if they are 
culturally responsive and FASD-informed, targeting the specific and general contributing factors of mental disorders (Salmon \& Clarren, 2011). Mental wellness can then be expected to emerge from the effort of aligning the right services, at the right time, for the right persons. Insufficient or partial knowledge by clinicians and policy makers regarding the complex influence of FASD on mental health care is concerning and requires direct attention.

For effective implementation of the current National Strategy amongst individuals with FASD, additional FASD-informed considerations would be beneficial. Currently, the risk is that the care provided will remain substandard until mental health clinicians recognize the uniqueness inherent in the large population of those with the complicating neurocognitive differences of FASD comorbid with an additional mental disorder diagnosis. Inadequate services leading to ineffective measures increase the cost of care and add to frustration among clinicians who struggle to best address the needs of their clients. Treatment plans that do not make considerations for underlying FASD have the potential to produce little benefit, leaving the clinician feeling ineffectual (McLennan, 2015; Mills, McLennan, \& Caza, 2006). This experience can be exasperating on all accounts. The resulting dejection and hopelessness for individuals living with FASD and mental health challenges is contrary to the desire for hope and restoration expressed in the National Strategy. If the National Strategy is meant to embrace inclusivity, it is important to recognize the influence of FASD on the lives of individuals as it relates to providing appropriate supports, services, and care.

In many ways, the National Strategy recognizes that it should cover the whole range of the population, not leaving those on the margins to fall through the cracks. It discusses "building on the many excellent initiatives already underway across the country," acknowledging several other existing strategies in place already to address unique needs (e.g., referencing the Nunavut Suicide Prevention Strategy when addressing suicide in Inuit youth; Mental Health Commission of Canada, 2012, p. 12). The current National Strategy does not include considerations for FASD, but when seeking to move towards an FASD-informed approach to mental health and addictions in Canada in the future, we do not need to start from scratch. Momentum can be gained by reviewing principles from other successful approaches that have been previously implemented. A number of successful strategies coming from different fields and jurisdictions have included prominent and distinctive FASD-informed considerations, including those from the Thunderbird Foundation (Are et al., 2010) and the community mental health initiatives of the Correctional Service of Canada (Forrester, Nolan, Stewart, Mullins, \& MacPherson, 2015). Designated strategic plans relating to FASD exist in the provinces of Alberta (Government of Alberta, 2008, 2013), British Columbia (Government of British Columbia, 2008) and Ontario (Ontario Network of Expertise, 2014). From a mental health and addictions viewpoint, some indications of FASD-informed considerations exist as well. For instance, the Government of Alberta's 2011 report entitled Creating Connections: Alberta's Addiction and Mental Health Strategy, emphasizes a focus on addressing complex needs and suggests "strengthen[ing] services for at-risk and under-served populations including prenatal and early-childhood programming, First Nation-, Métis-, and Inuit-specific programs, home visitation, and support for children with disabilities and Fetal Alcohol Spectrum Disorder" (Government of Alberta, 2011, p. 17).

Without necessarily duplicating one another, the existing strategies and approaches can inform and support each other in moving toward a mutually beneficial end. Table 1 highlights a few key features of some recent Canadian sources, including programs, reports, and strategies, that could be seen as supporting 


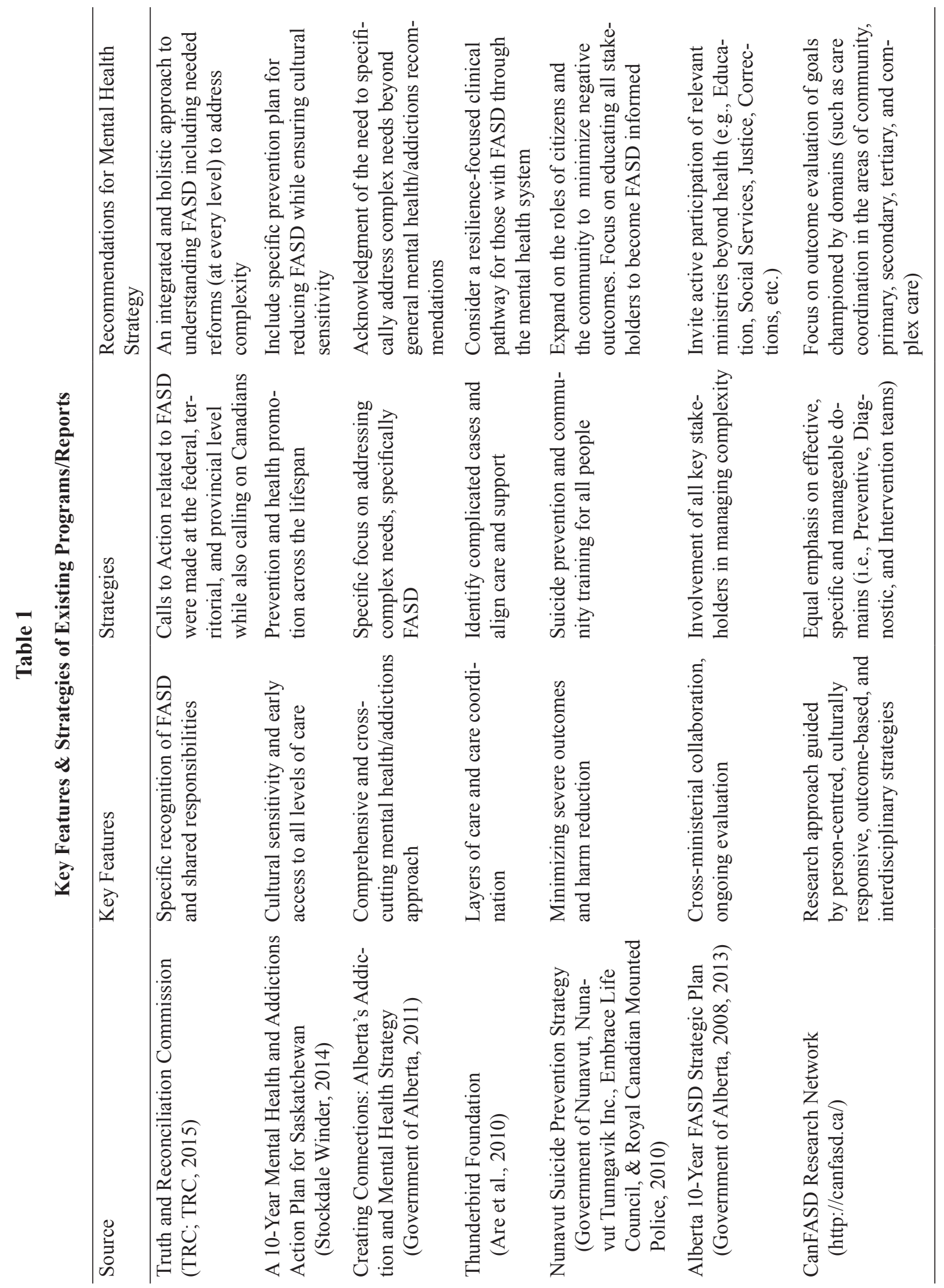


approaches for the current National Strategy to be more responsive to individuals with FASD. (Please note that this table is not intended to be comprehensive, but rather to exemplify a variety of features and strategies that could be seen as beneficial for providing a more FASD-informed lens to the current National Strategy.)

\section{MOVING FORWARD WITH FASD}

In Canada, the platform for the advancement of FASD would benefit from seeking to unify the collective experiences of those living with the disorder, service delivery, research efforts, and dynamic knowledge translation. For this to be achieved, it is essential to create space for a free-flowing relationship between those providing services, researchers, and policy makers while prioritizing the perspectives of those with lived experiences and their families. For research to best address the needs of individuals with FASD, engaging in patient-oriented approaches will continue to be constructive for stimulating innovation and producing the most relevant discoveries. It is important to intentionally develop connection points in order to collectively generate priorities and develop creative solutions that meet the needs of individuals living with FASD (e.g., workshops that pull together multiple stakeholders to serve as collaborative spaces and high-impact training; see Stewart, 2015). Another example includes the research organized by the Canada FASD Research Network (for more info about CanFASD visit http://canfasd.ca/). CanFASD strives to bring together sections of academia, front-line professionals, and individuals with lived experiences and their families for the purposes of generating collaborative research goals, ideas, and outcomes directed towards understanding FASD for the well-being of patients, families, and society at large. So far, the payoff of these relationships include updated diagnostic guidelines that are recognized and esteemed worldwide (Cook et al., 2015). These guidelines, which were recently updated on account of the rapidly increasing evidence, have been recognized as of high scientific rigor (Hoyme et al., 2016). Not surprising, then, is the fact that other countries have adopted these guidelines with minor geographical modifications. The model of FASD prevention developed in Canada by CanFASD is the leading paradigm for the understanding and application of prevention in the field (Poole, 2010; Rutman et al., 2014). Effective interventions with wide applicability across schools, work, and society were developed in Canada and constitute the most advanced strategies yet available for FASD treatment (Pei, Denys, Hughes, \& Rasmussen, 2011; Pei \& Kerns, 2012). These outcomes are based on an organizational research approach that seeks to listen to individuals with FASD and their families to generate research which is person-centred, culturally responsive, outcomebased, and interdisciplinary. These pursuits lend themselves as good models for the advancement of the mental health system to become more FASD-informed. Given the relationship between FASD and mental disorder, and its prevalence within the mental health system, actively acknowledging FASD in the strategies we use to approach mental wellness will have trickle-down benefits for the comprehensiveness and future advancements of our current mental health system.

It is widely recognized that stigma decreases with the visibility and openness to discussion of which a disorder has the benefit (Rüsch, Angermeyer, \& Corrigan, 2005; Sartorius, 2007). The level of stigma associated with FASD is still regrettably high. The anti-stigma campaign strategies of the mental health system targeting the stigma of mental disorder can and should be emulated in the field of FASD. This approach is a strong component of the National Strategy and should be seen as an opportunity where effective tactics that produced stigma reduction surrounding mental health can be investigated and adapted for implementation 
for FASD. Additionally, perhaps FASD could be incorporated into the stigma reduction work being done in mental health so as to align the two, rather than keeping them separate.

\section{BUILDING UPON CHANGING DIRECTIONS, CHANGING LIVES}

Saskatchewan is one of the Canadian provinces that formulated and implemented a mental health strategy subsequent to the publication of Changing Directions, Changing Lives. Released in December of 2014, Working Together For Change is a 10-year mental health and addictions action plan for Saskatchewan (Stockdale Winder, 2014). The process was led by a co-chair of The Mental Health Commission of Canada (Dr. Fern Stockdale-Winder) and deployed a collaborative and consultative process similar to the one used to develop the National Strategy. The many consultations by different subcommittees and early involvement of key stakeholders were also reminiscent of the steps outlined in the development of Changing Directions, Changing Lives at the national level. Government approval of the recommendations and the types of recommendations mirror the National Strategy. It is a testimony to the influence of the national Mental Health Strategy that principles such as access, person-centred approaches, accountability, and cultural sensitivity were central to the development of the Saskatchewan plan.

Focused on promotion and prevention, the Saskatchewan plan detailed stories and examples of how the plan was developed with the people of Saskatchewan in mind. The plan was birthed from the recognition of the diversity of Saskatchewan that emerged through early consultations. In that plan, mental health and addictions were considered inseparable, and FASD was recognized as an implication of alcohol misuse, though no specific considerations or recommendations related to FASD were made. The report suggestions included a cross-sectoral coordination of services (as noted in Table 1) and focused heavily on recovery from mental illness, with the Commissioner concluding that the fundamental goal is "to promote recovery to the greatest extent possible, improve mental well-being, and ultimately enhance the overall health and vibrancy of our communities and our province" (Stockdale Winder, 2014, p. 6). The National Strategy will continue to serve as a blueprint for the emergence of other plans and strategies. Fulfilling the mandate of the Mental Health Commission of Canada, the National Strategy allows other jurisdictions to dream, attempt, and develop similar or better plans. For those considering the National Strategy as a foundation for the development of future planning, the addition of a specific FASD approach would be a valuable next step.

Another example that is worth noting here is a report put forward by the Thunderbird Partnership in Canada called Honouring Our Strengths: A Renewed Framework to Address Substance Use Issues Among First Nations People in Canada (Are et al., 2010). Working through action committees from 2007, the discussions on how to reduce the significant disadvantages faced by the community and the resulting consequences of mental health problems resulted in a six-element plan. Contained in the elements is the recognition of several levels of severity and complexity of mental well-being, a determination of the investment needed by all in society, and the identification of the services needed to meet the needs. These elements reflect principles similar to those of Changing Directions, Changing Lives, and among them are concepts such as shared responsibility, cultural safety, community, and a focus on individual resilience, all of which are inline with the National Strategy's thoughts on the principals of promotion, prevention, and recovery. Another similarity between the Thunderbird stance and the National Strategy is the focus on youth as an investment 
in a shared future. The Thunderbird elements do, however, offer specific recommendations about how to prevent, identify, and intervene for people with FASD. Specialized services were recommended for those with FASD and their families. Element five (which addresses those with severe issues) contains the highest level of recognition ascribed to FASD in the document. The service and support component appropriately addresses the requirement for care coordination and cultural responsivity. The recognition of FASD in such a manner should serve as an example for others planning to develop an overarching strategy. Addiction is recognized by other strategies, but the Thunderbird Foundation gives FASD its due recognition.

\section{REVISITING THE NATIONAL STRATEGY IN LIGHT OF TRC CALLS TO ACTION}

The National Strategy was released during an era of reconciliation in Canada. Specifically, the National Strategy was published during a time in which the Truth and Reconciliation Commission of Canada (the TRC) was undertaking an investigation into the legacies of the residential school program. The multi-year investigation resulted in the release of the Calls to Action in June 2015 and then the full report in December 2015 (Truth \& Reconciliation Commission of Canada, 2015). The issue of mental health and overall wellness is first raised in Call to Action 19:

19. We call upon the federal government, in consultation with Aboriginal peoples, to establish measurable goals to identify and close the gaps in health outcomes between Aboriginal and non-Aboriginal communities, and to publish annual progress reports and assess long-term trends. Such efforts would focus on indicators such as: infant mortality, maternal health, suicide, mental health, addictions, life expectancy, birth rates, infant and child health issues, chronic diseases, illness and injury incidence, and the availability of appropriate health services.

While mental health is raised numerous times in the Calls to Action, it is Call to Action 19 that indicates that health disparities require attention through identification of issues and also through the alignment of appropriate supports and services. Further, Calls to Action 33 and 34 explicitly address FASD:

33. We call upon the federal, provincial, and territorial governments to recognize as a high priority the need to address and prevent Fetal Alcohol Spectrum Disorder (FASD), and to develop, in collaboration with Aboriginal people, FASD preventive programs that can be delivered in a culturally appropriate manner.

34. We call upon the governments of Canada, the provinces, and territories to undertake reforms to the criminal justice system to better address the needs of offenders with Fetal Alcohol Spectrum Disorder (FASD) including:

i. Providing increased community resources and powers for courts to ensure that FASD is properly diagnosed, and that appropriate community supports are in place for those with FASD.

ii. Enacting statutory exemptions from mandatory minimum sentences of imprisonment for offenders affected by FASD.

iii. Providing community, correctional, and parole resources to maximize the ability of people with FASD to live in the community.

iv. Adopting appropriate evaluation mechanisms to measure the effectiveness of such programs and ensure community safety. 
The TRC Calls to Action affirm that one of the adverse consequences of FASD is criminal justice involvement. The TRC Calls to Action bring together the need for prevention and criminal justice reform efforts. The document also notes that reconciliation is the work of all Canadians. It is imperative to understand that FASD is not specifically an Indigenous problem, but rather a problem crosscutting the entire population (Fitzpatrick et al., 2012; Tait, 2013). That said, the TRC does offer a unique occasion for everyone in Canada to pay attention to FASD, as the Calls to Action are for high priority status at the policy level and a concurrent community-level response. The TRC framework also highlights the fact that effective and appropriate responses to FASD must be integrated and contextualized. Accordingly, the TRC Calls to Action offer another way of thinking about how to integrate FASD into broader projects; for example, the TRC calls for a response that brings together prevention and intervention while also recognizing the effects of the condition. It seeks a multi-level approach to FASD. The way that the TRC approaches FASD can offer important insights to the approach to mental health and FASD in Canada. The common themes between Changing Directions, Changing Lives and the TRC's holistic and integrated Calls to Action include promotion, prevention, and increased community resources. The strategic directions of the TRC report emphasize that it is important to "work with First Nations, Inuit, and Métis to address their mental health needs, acknowledging their distinct circumstances, rights, and cultures. By calling for access to a full continuum of culturally safe mental health services, the National Strategy for Canada can contribute to truth, reconciliation, and healing from intergenerational trauma" (Mental Health Commission of Canada, 2012, p. 11).

An integrated and holistic approach to mental health and wellness would be FASD-informed so as to best identify appropriate supports and services. The TRC report calls for a recognition of health inequities when speaking about mental health (\#19) and concurrently points to the deep impact FASD has on the lives of individuals (\#33 and \#34). The TRC report serves as a reminder about the broader contexts that inform mental health and wellness. It also illustrates the need for culturally responsive programs and supports that are attentive to both the shared and varied histories that come to the forefront when discussing mental health and wellness (Di Lallo, 2014).

\section{CONCLUSION}

The foreword of Changing Directions, Changing Lives: The Mental Health Strategy for Canada indicates that "there now exists an historic opportunity to make a difference. It will not be easy, but the winds of change have been swirling about the mental health system for many years. We can and must promote mental health in all walks of life, and do everything possible to reduce people's risk of developing a mental health problem or illness, or of becoming so desperate as to contemplate suicide" (Mental Health Commission of Canada, 2012, p. 3). This article argues that there is a need to think about FASD as it relates to mental health in Canada, and that to ignore FASD is detrimental to the success of strategic approaches to mental health. Indeed, individuals with FASD are at risk for suicide and other adverse mental health outcomes. However, with an integrated approach to mental health and wellness - an approach that is FASD-informed - we can hope to see better health outcomes for individuals who receive a more accurate diagnosis. This will, in turn, help clinicians and individuals to identify the most appropriate supports and strategies. The National Strategy described an "historic opportunity" to bring about change in 2012. This article points to the need for ongoing analysis and engagement so that FASD-informed care can be rigorously embraced and deployed 
to all communities in Canada. The release of the TRC Calls to Action in 2015 served as a gentle reminder that wellness practices must be culturally responsive and take into account any cultural-historical context. Whether thinking about the particular challenges of mental health in First Nations, Inuit, and Métis communities or in the broader, more general population, adding FASD-informed considerations to the delivery of mental health services can only serve to promote the inclusivity that was initially at the heart of the 2012 National Strategy document.

\section{REFERENCES}

American Psychiatric Association. (2013). Diagnostic and statistical manual of mental disorders (5th ed.). Washington, DC: Author.

Are, W. W., Many Hands, O. F., Exhibition, C. A. B. P., Path, I. K. R., Bryce, W. W. P. H., Do, W. Y. C., \& Gallery, B. W. (2010). Honouring our strengths: A renewed framework to address substance abuse issues among First Nations people in Canada. Health Canada.

Arnold, K., Burke, M., Decker, A., Herzberg, E., Maher, M., Motz, K.,...Ybarra, M. (2013). Fetal alcohol spectrum disorders: Knowledge and screening practices of university hospital medical students and residents. Journal of Popular Therapeutic Clinical Pharmacology, 20(1), e18-25.

Chapman, J. L. (2008). Fetal Alcohol Spectrum Disorder (FASD) and the criminal justice system: An exploratory look at current treatment practices. Unpublished master's thesis. School of Criminology, Simon Fraser University.

Chasnoff, I. J., Wells, A. M., \& King, L. (2015). Misdiagnosis and missed diagnoses in foster and adopted children with prenatal alcohol exposure. Pediatrics, 135(2), 264-270.

Chudley, A. E., Conry, J., Cook, J. L., Loock, C., Rosales, T., \& LeBlanc, N. (2005). Fetal alcohol spectrum disorder: Canadian guidelines for diagnosis. Canadian Medical Association Journal, 172(Suppl. 5), S1-S21.

Chudley, A. E., Kilgour, A. R., Cranston, M., \& Edwards, M. (2007). Challenges of diagnosis in fetal alcohol syndrome and fetal alcohol spectrum disorder in the adult. doi:10.1002/ajmg.c.30140

Cook, J. L., Green, C. R., Lilley, C. M., Anderson, S. M., Baldwin, M. E., Chudley, A. E.,...Lutke, J. (2015). Fetal alcohol spectrum disorder: A guideline for diagnosis across the lifespan. Canadian Medical Association Journal. doi:10.1503/cmaj.141593

Di Lallo, S. (2014). Prenatal care through the eyes of Canadian Aboriginal women. Nursing for Women's Health, 18(1), 38-46.

Fast, D. K., \& Conry, J. (2011). Understanding the similarities and differences between fetal alcohol spectrum disorder and mental health disorders. Ottawa, ON: Research and Statistics Division, Department of Justice Canada.

Fast, D. K., Conry, J., \& Loock, C. A. (1999). Identifying fetal alcohol syndrome among youth in the criminal justice system. Journal of Developmental \& Behavioral Pediatrics, 20(5), 370-372.

Fitzpatrick, J. P., Elliott, E. J., Latimer, J., Carter, M., Oscar, J., Ferreira, M.,...Salter, C. (2012). The Lililwan Project: Study protocol for a population-based active case ascertainment study of the prevalence of fetal alcohol spectrum disorders (FASD) in remote Australian Aboriginal communities. BMJ Open, 2(3). doi:10.1136/ bmjopen-2012-000968

Forrester, P., Nolan, A., Stewart, L., Mullins, P., \& MacPherson, P. H. (2015). Promising intervention approaches for offenders with cognitive deficits related to Fetal Alcohol Spectrum Disorder (FASD) and other neuropsychological disorders (research report R-340). Ottawa, ON: Correctional Service of Canada.

Government of Alberta. (2008). FASD 10-year strategic plan. http://fasd.alberta.ca/documents/FASD-10-year-plan.pdf

Government of Alberta. (2011). Creating Connections: Alberta's Addiction and Mental Health Strategy. www.health. alberta.ca/documents/Creating-Connections-2011-Strategy.pdf

Government of Alberta. (2013). Year 5 evaluation of the Government of Alberta's FASD 10-year strategic plan. http:// fasd.alberta.ca/documents/2-Year_5_Evaluation_of_the_FASD_10-Year_Strategic_Plan_WEB.pdf

Government of British Columbia. (2008). Fetal Alcohol Spectrum Disorder: Building on strengths: A provincial plan for British Columbia. www2.gov.bc.ca/assets/gov/health/managing-your-health/fetal-alcohol-spectrum-disorder/ fetal_alcohol_spectrum_disorder_building_strengths.pdf 
Government of Nunavut, Nunavut Tunngavik Inc., Embrace Life Council, \& Royal Canadian Mounted Police. (2010). Nunavut suicide prevention strategy. www.naho.ca/documents/it/2010-10-26-Nunavut-Suicide-PreventionStrategy-English.pdf

Grant, T. M., Brown, N. N., Dubovsky, D., Sparrow, J., \& Ries, R. (2013). The impact of prenatal alcohol exposure on addiction treatment. Journal of Addiction Medicine, 7(2), 87-95.

Hoyme, H. E., Kalberg, W. O., Elliott, A. J., Blankenship, J., Buckley, D., Marais, A.-S.,...Abdul-Rahman, O. (2016). Updated clinical guidelines for diagnosing fetal alcohol spectrum disorders. Pediatrics, 138(2). doi:10.1542/ peds.2015-4256.

Huggins, J. E., Grant, T., \& Streissguth, A. P. (2008). Suicide attempts among adults with fetal alcohol spectrum disorders: Clinical considerations. Mental Health Aspects of Developmental Disabilities, 11(2), 33-42.

Jones, K., \& Smith, D. (1973). Recognition of the fetal alcohol syndrome in early infancy. The Lancet, 302(7836), 999-1001.

May, P. A., Gossage, J. P., Kalberg, W. O., Robinson, L. K., Buckley, D., Manning, M., \& Hoyme, H. E. (2009). Prevalence and epidemiologic characteristics of FASD from various research methods with an emphasis on recent in-school studies. Developmental Disabilities Research Reviews, 15(3), 176-192.

McLennan, J. D. (2015). Misattributions and potential consequences: The case of child mental health problems and fetal alcohol spectrum disorders. Canadian Journal of Psychiatry, 60(12), 587.

Mental Health Commission of Canada. (2012). Changing directions, changing lives: The mental health strategy for Canada. Calgary, AB: Author.

Mills, R. M., McLennan, J. D., \& Caza, M. M. (2006). Mental health and other service use by young children with fetal alcohol spectrum disorder. Journal of FAS International, 4(1), 1-11.

Nash, K., Koren, G., \& Rovet, J. (2009). Neurobehavioural Screening Tool (NST): Guidelines and Scoring. www. fasdnorcal.org/upload/60_NeurobehaviouralScreeningToolEN.pdf

Nash, K., Rovet, J., Greenbaum, R., Fantus, E., Nulman, I., \& Koren, G. (2006). Identifying the behavioural phenotype in fetal alcohol spectrum disorder: Sensitivity, specificity and screening potential. Archives of Women's Mental Health, 9(4), 181-186.

O’Connor, M. J., \& Paley, B. (2009). Psychiatric conditions associated with prenatal alcohol exposure. Developmental Disabilities Research Reviews, 15(3), 225-234.

Ontario Network of Expertise. (2014). Fetal Alcohol Spectrum Disorder (FASD): A call to action in Ontario. www. fasdontario.ca/cms/wp-content/uploads/2014/01/FASD-call-to-action-r6-HiRes.pdf.

Pei, J., Denys, K., Hughes, J., \& Rasmussen, C. (2011). Mental health issues in fetal alcohol spectrum disorder. Journal of Mental Health, 20(5), 473-483.

Pei, J., \& Kerns, K. (2012). Using games to improve functioning in children with fetal alcohol spectrum disorders. Games for Health: Research, Development, and Clinical Applications, 1(4), 308-311.

Poole, N. (2010). Bringing a women's health perspective to FASD prevention. In E. P. Riley, S. Clarren, J. Weinberg, \& E. Jonsson (Eds.), Fetal alcohol spectrum disorder: Management and policy perspectives of FASD, 161-174. doi:10.1002/9783527632510.ch9.

Popova, S., Lange, S., Bekmuradov, D., Mihic, A., \& Rehm, J. (2011). Fetal alcohol spectrum disorder prevalence estimates in correctional systems: A systematic literature review. Canadian Journal of Public Health/Revue Canadienne de Santé Publique, 336-340.

Popova, S., Lange, S., Shield, K., Mihic, A., Chudley, A. E., Mukherjee, R. A.,...Rehm, J. (2016). Comorbidity of fetal alcohol spectrum disorder: A systematic review and meta-analysis. The Lancet, 387(10022), 978-987. doi: 10.1016/S0140-6736(15)01345-8.

Roach, K., \& Bailey, A. (2009). The relevance of fetal alcohol spectrum disorder and the criminal law from investigation to sentencing. University of British Columbia Law Review, 42, 1-68.

Roozen, S., Peters, G. J. Y., Kok, G., Townend, D., Nijhuis, J., \& Curfs, L. (2016). Worldwide prevalence of fetal alcohol spectrum disorders: A systematic literature review including meta-analysis. Alcoholism: Clinical and Experimental Research, 40(1), 18-32.

Rüsch, N., Angermeyer, M. C., \& Corrigan, P. W. (2005). Das Stigma psychischer Erkrankung: Konzepte, Formen und Folgen [The stigma of mental illness: Concepts, forms, and consequences]. Psychiatrische Praxis, 32(5), 221-232. doi:10.1055/s-2004-834566 
Rutman, D., Poole, N., Hume, S., Hubberstey, C., \& Van Bibber, M. (2014). Building a framework for evaluation of Fetal Alcohol Spectrum Disorder prevention and support programs: A collaborative Canadian project. International Journal of Alcohol and Drug Research, 3(1), 81-89.

Salmon, A., \& Clarren, S. K. (2011). Developing effective, culturally appropriate avenues to FASD diagnosis and prevention in northern Canada. International Journal of Circumpolar Health, 70(4), 428-433.

Sartorius, N. (2007). Stigma and mental health. The Lancet, 370(9590). https://doi.org/10.1016/S0140-6736(07)61245-8

Stade, B., Ali, A., Bennett, D., Campbell, D., Johnston, M., Lens, C.,...Koren, G. (2008). The burden of prenatal exposure to alcohol: Revised measurement of cost. Canadian journal of clinical pharmacology/Journal canadien de pharmacologie clinique, 16(1), e91-102.

Stewart, M. (2015). Workshop scribbles, policy work and impact: Anthropological sensibilities in praxis at an FASD workshop. Anthropology in Action. 12(2): 24-35.

Stockdale Winder, F. (2014). Working together for change: A 10-year mental health and addictions action plan for Saskatchewan. Government of Saskatchewan.

Streissguth, A., Barr, H., Kogan, J., \& Bookstein, F. (1996). Understanding the occurrence of secondary disabilities in clients with fetal alcohol syndrome (FAS) and fetal alcohol effects (FAE). Final report to the Centers for Disease Control and Prevention (CDC). University of Washington, Seattle, WA.

Tait, C. L. (2013). Resituating the ethical gaze: Government morality and the local worlds of impoverished Indigenous women. International Journal of Circumpolar Health, 72. doi:10.3402/ijch.v72i0.21207

Thanh, N. X., Jonsson, E., Salmon, A., \& Sebastianski, M. (2014). Incidence and prevalence of fetal alcohol spectrum disorder by sex and age group in Alberta, Canada. Journal of Popular Therapeutics and Clinical Pharmacology, 21(3), e395-404.

Truth and Reconciliation Commission of Canada. (2015). Honouring the truth, reconciling for the future: Summary of the final report of the Truth and Reconciliation Commission of Canada. Winnipeg: Author.

Yates, W. R., Cadoret, R. J., Troughton, E. P., Stewart, M., \& Giunta, T. S. (1998). Effect of fetal alcohol exposure on adult symptoms of nicotine, alcohol, and drug dependence. Alcoholism: Clinical and Experimental Research, 22(4), 914-920. 